ISSN Print : 1411 - $951 \mathrm{X}$, ISSN Online : 20503-1716

Jurnal Ergonomi Indonesia

(The Indonesian Journal of Ergonomic)

\author{
ABSTRACT \\ USE OF REDESIGN BREASTFEEDING PILLOW TO IMPROVE MOTIVATION \\ OF BREASTFEEDING MOTHERS AND BABIES SATISFACTION, ALSO REDUCE \\ FATIGUE AND MUSCOLOSKELETAL COMPLAINTS ON POST PARTUM \\ MOTHERS \\ Ni Wayan Muliarthini ${ }^{1}$; I Dewa Putu Sutjana ${ }^{2}$; I Putu Gede Adiatmika ${ }^{3}$ \\ muliarthiniwayan@ymail.com \\ Student $^{1}$; Supervisor $1^{2}$; Supervisor $2^{3}$ \\ Program Studi Ergonomi-Fisiologi Kerja, Program Pascasarjana Udayana University
}

\begin{abstract}
Breastfeeding is a very important activity for both mother and baby. In the breastfeeding state the relationship between mother and baby will be tight and close. The old method and also duration of breastfeeding can cause fatigue, shoulder muscle tension, and soreness / stiffness in breastfeeding mothers. Problems due to absence of the use of pillow when mother breastfeed and mothers only depending on her limb to sustain baby when breastfeeding. In this case we need an ergonomic pillow to help mother feeding her baby. The purpose of this research is to investigate the use of redesigning nursing pillow can reduce fatigue, musculoskeletal complaints in breastfeeding mothers, to determine the use redesigning nursing pillow increase the motivation of mothers to breastfeed the baby as well as increase the satisfaction of nursing infants.

This research held in as an experimental research draft of pre and post control group design. Samples that were included in this study was 22 people divided into two groups. The control group will breastfeeding using older model nursing pillow, while the another group will use the new redesign nursing pillow. Data analysis using t-test paried significance level of $5 \%$.

The result showed mother's motivation after breastfeeding in both groups increased, the control group $(18.27 \pm 2.370)$ and the treatment group $(15.45 \pm 1.809)$. Baby satisfaction in the control group $(11.09 \pm 0.943)$, while the treatment group $(12.27 \pm 0.904)$. Exhausted mother's in the control group $(39.64 \pm 2.803)$, while the treatment group $(32.64 \pm 1.504)$. Musculoskeletal disorders that mother's felt in the control group $(37.54 \pm 1.694)$, while the treatment group $(30.81 \pm 2.136)$.

Based on the study can be concluded that redesign breastfeeding pillow can giving impact to increase motivation and baby satisfaction and also decrease fatigue and musculoskeletal complain/disorder that mothers can feel. So hopefully by using this nursing pillow design maximizes mothers to breastfeed
\end{abstract}

Keyword: Redesign Pillow, Motivation, Baby Satisfaction, Fatigue And Musculoskeletal Complaints 
ISSN Print : $1411-951 \mathrm{X}$, ISSN Online : 20503-1716

Jurnal Ergonomi Indonesia

(The Indonesian Journal of Ergonomic)

\title{
ABSTRAK \\ PENGGUNAAN REDESAIN BANTAL MENYUSUI MENINGKATKAN MOTIVASI \\ IBU MENYUSUI DAN KEPUASAN BAYI SERTA MENGURANGI KELELAHAN DAN KELUHAN MUSKULOSKELETAL IBU POST PARTUM
}

\author{
Ni Wayan Muliarthini ${ }^{1}$; I Dewa Putu Sutjana ${ }^{2}$; I Putu Gede Adiatmika ${ }^{3}$ \\ muliarthiniwayan@ymail.com \\ Mahasiswa $^{1}$; Pembimbing $1^{2}$; Pembimbing2 ${ }^{3}$ \\ Program Studi Ergonomi-Fisiologi Kerja, Program Pascasarjana Universitas Udayana
}

\begin{abstract}
Abstrak
Menyusui merupakan aktivitas yang sangat penting bagi ibu dan bayi. Dalam proses menyusui terjadi hubungan yang erat dan dekat antara ibu dan bayi. Cara dan lama menyusui bayi dapat menyebabkan kelelahan pada ibu menyusui, ketegangan otot bahu serta rasa pegal/ kaku.

Permasalahan karena tidak adanya penggunaan bantal saat ibu menyusui dan ibu hanya mengandalkan anggota tubuhnya untuk menopang tubuh bayi saat menyusui. Kondisi ini diperlukan bantal yang ergonomis ketika ibu menyusui bayi. Tujuan dari penelitian ini adalah untuk mengetahui penggunaan redesain bantal menyusui dapat mengurangi kelelahan, keluhan muskuloskeletal pada ibu menyusui, untuk mengetahui penggunaan redesain bantal menyusui meningkatkan motivasi ibu untuk menyusui bayi serta meningkatkan kepuasan bayi menyusui.

Penelitian ini dilakukan di RSU Puri Raharja. adalah penelitian eksperimental menggunakan rancangan pre dan post control group desain (control group design) Sampel yang dilibatkan berjumlah 22 orang dibagi jadi 2 kelompok. Kelompok kontrol menyusui menggunakan bantal menyusui model lama, sedangkan kelompok perlakuan menggunakan redesain bantal menyusui. Analisis data menggunakan uji t-paried taraf signifikasi 5\%.

Hasil penelitian menunjukan motivasi ibu setelah menyusui pada kedua kelompok terjadi peningkatan, kelompok kontrol (18,27 $\pm 2,370)$ dan kelompok perlakuan $(15,45 \pm 1,809)$. Kepuasan bayi pada kelompok kontrol $(11,09 \pm 0,943)$ sedangkan pada kelompok perlakuan $(12,27 \pm 0,904)$. Kelelahan ibu pada kelompok kontrol $(39,64 \pm 2,803)$ sedangkan pada kelompok perlakuan $(32,64 \pm 1,504)$. Keluhan muskuloskelatel ibu pada kelompok kontrol $(37,54 \pm 1,694)$ sedangkan pada kelompok perlakuan $(30,81 \pm 2,136)$.

Disimpulkan bahwa redesain bantal menyusui dapat meningkatkan motivasi dan kepuasan bayi dan menurunkan kelelahan dan keluhan muskuloskletal pada ibu. Sehingga diharapkan dengan menggunakan desain bantal menyusui ini dapat memaksimalkan ibu untuk menyusui bayinya
\end{abstract}

Kata kunci : Redesain Bantal, Motivasi, Kepuasan Bayi, Kelelahan Dan Keluhan Muskuloskelatal 


\section{Latar Belakang}

Menyusui merupakan aktivitas yang sangat penting bagi ibu dan bayi. Dalam proses menyusui terjadi hubungan yang erat dan dekat antara ibu dan bayi. Pemberian ASI dalam enam bulan pertama diatur pada ketetapan Peraturan Pemerintah Republik Indonesia Nomor 33 Tahun 2012. ASI Eksklusif adalah ASI yang diberikan kepada bayi sejak dilahirkan selama 6 bulan tanpa menambahkan atau mengganti makanan atau minuman lain.

Motivasi adalah hasil dari kumpulan kekuatan internal dan eksternal yang menyebabkan orang akan memilih jalan untuk bertindak yang sesuai dan menggunakan prilaku tertentu (Newstrom, 2011 dalam Wibowo 2014). Motivasi seorang ibu dalam menyusui pada umumnya berasal dari dalam yaitu berupa kesadaran dan kemauan ibu jika berasal luar diri seperti keluarga, masyarakat atau tenaga kesehatan motivasi yang diberikan berupa pemberian informasi.

Dari delapan aspek ergonomi : gizi, pemanfaatan tenaga otot, sikap kerja, kondisi lingkungan, kondisi waktu, kondisi sosial, kondisi informasi dan interaksi manusia-mesin (Manuaba,2005), tiga aspek yang sangat kuat yang dikaji sangat mempengaruhi keberhasilan ibu untuk menyusui bayi yaitu 1) Ibu menyusui memerlukan tambahan nutrisi sebesar 800 kalori/hari pada 6 bulan pertama. 6 bulan selanjutnya 500 kalori/hari (Suherni,2009); 2) Pengasuhaan yang dilakukan ibu pada bayi memerlukan kekuatan fisik dan psikis setiap harinya; 3) Sikap ibu saat menyusui dapat menyebabkan kelelahan.

Menurut Tawarka (2004), kelelahan merupakan suatu mekanisme perlindungan agar terhindar dari kerusakan lebih lanjut, dengan ini terjadilah pemulihan setelah istirahat. Kelelahan merupakan suatu perasaan subjektif. Kelelahan suatu kondisi yang disertai penurunan efisiensi dan kebutuhan dalam bekerja (Budiono, 2003). Faktor-Faktor Penyebab Kelelahan Otot

1. Penumpukan asam laktat

2. Pengosongan penyimpanan ATP dan PC

\section{Pengosongan Simpanan Glikogen Otot}

Pada saat menjadi ibu baru, ibu sering mengalami rasa lelah/letih. kondisi ini akan membuat kesulitan pada ibu dalam beradaptasi dalam membesarkan bayi.

Post partum adalah masa atau waktu sejak bayi dilahirkan dan plasenta keluar lepas dari rahim, sampai enam minggu berikutnya, yang disertai dengan pulihnya kembali organ-organ yang berkaitan dengan kandungan, yang mengalami perubahan seperti sembuhnya luka yang berkaitan saat melahirkan (Suherni, 2009).

Musculoskeletal Disorder (MSDs) adalah kelainan yang disebabkan penumpukan cidera atau kerusakan kecil pada sistem musculoskeletal akibat trauma berulang yang setiap kalinya tidak sempat sembuh secara sempurna, sehingga membentuk kerusakan cukup besar untuk besar dan menimbulkan rasa sakit (Humanteck, 1995).

Keluhan muskuloskeletal pada umumnya terjadi karena kontraksi otot statis yang berlebihan akibat pemberian beban kerja yang terlalu berat dengan durasi pembebanan yang panjang. Sebaliknya keluhan otot kemungkinan tidak terjadi apabila kontraksi otot hanya berkisar antara 15-20\% dari kekuatan otot maksimum. Namun, apabila kontraksi otot melebihi 20\% maka peredaran darah ke otot berkurang menurut tingkat kontraksi yang dipengaruhi oleh besarnya tenaga yang diperlukan. Suplai oksigen ke otot menurun, proses metabolisme karbohidrat terhambat dan sebagai akibatnya terjadi penimbunan asam laktat yang menyebabkan timbulnya rasa nyeri di otot menurut Utomo (2012). 


\section{Jurnal Ergonomi Indonesia}

\section{(The Indonesian Journal of Ergonomic)}

Antropometri adalah ilmu yang bekaitan dengan pengukuran dimensi dan cara untuk mengaplikasikan karakteristik tertentu dari tubuh manusia (Roebuck, 1994 dalam Wardani 2004 ).

Ergonomi mengajarkan bahwa desain dari pada task ( peralatan ), organisasi (aktivitas) dan lingkungan, harus benarbenar didasari oleh kemampuan fungsional dari manusia yang mengunakannya sehingga manusia bisa memanfaaatkanya semua fungsi secara optimal dan maksimal ( Manuaba, 2003). Bantal menyusui adalah sejenis bantal yang bisa memberikan banyak manfaat dan membantu ibu ketika menyusui bayi.

Menurut Pheasent (2003), tujuan bantal menyusui adalah memberikan dukungan yang stabil pada tubuh, yaitu :

a. Nyaman.

b. Fisiologi.

c. Sesuai fungsi.

Desain bantal yang dirancang mengacu pada ukuran antropometri, yaitu :

a. Tinggi badan.

Tinggi badan adalah jarak batas atas kepala sampai dengan kaki.

b. Tinggi siku ke siku

Tinggi siku ke siku adalah jarak horizontal dari bagian siku kiri sampai bagian siku kanan.

c. Tinggi siku duduk ( TSD ).

Tinggi siku duduk adalah jarak vertikal dari permukaan alas duduk sampai ujung bawah siku lengan atas membentuk sudut siku-siku dengan lengan bawah.

Redesain bantal menyusui yang digunakan memiliki spesifikasi : bahan dasar spon ( dacron ), dilapisi perlak

Ukuran bantal : diameter dalam $16 \mathrm{~cm}$, diameter Luar $51 \mathrm{~cm}$, tinggi bantal awal adalah $12 \mathrm{~cm}$ akan di redesign menjadi 22 $\mathrm{cm}$, berat bantal $1000 \mathrm{gr}$.

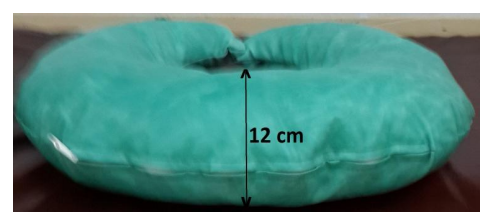

\section{Rumusan Masalah}

a. Apakah penggunaan redesain bantal menyusui meningkatkan motivasi ibu untuk menyusui bayi?

b. Apakah penggunaan redesain bantal menyusui meningkatkan kepuasan bayi menyusui?.

c. Apakah penggunaan redesain bantal menyusui dapat mengurangi kelelahan pada ibu menyusui?.

d. Apakah penggunaan redesain bantal menyusui dapat mengurangi keluhan muskuloskeletal pada ibu menyusui?.

\section{Metode Penelitian}

Penelitian ini adalah penelitian eksperimental menggunakan rancangan pre dan post control group desain ( Bakta 1997 ) yang dilakukan di RSU Puri Raharja yang terletak di Jalan WR Supratman No 14 Denpasar, selama 3 bulan yang dimulai pada bulan Maret s/d Mei 2016.

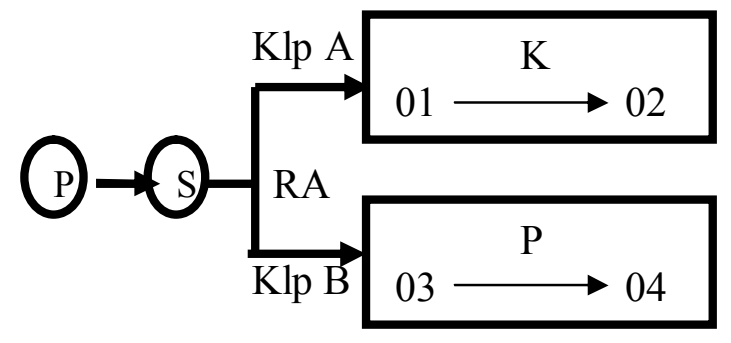

Gambar 1 Rancangan Penelitian

Sampel dari subjek penelitian yang dilibatkan merupakan sampel dari sebagian populasi yang dipilih berdasarkan kriteria sampel penelitian. Sampel penelitian diambil secara random dengan bilangan acak dan besaran sampel dihitung dengan rumus sebagai berikut ( Pocock, 2008 ). Berdasarkan studi pendahuluan yang dilakukan jumlah sampel sebesar 10,32 untuk mengantisipasi terjadinya drop out selama pelaksanaan penelitian jumlah sampel ditambah $10 \%$ ( Arikunto, 1998) menjadi $10,32+(10 \%=1,03)=$ 11,33 dibulatkan menjadi 11 sampel. 
(The Indonesian Journal of Ergonomic)

Teknik penentuan sampel dalam penelitian ini mengunakan teknik sampel homogeny (Stratified random sampling).

Variabel-variabel dalam penelitian ini dapat diidentifikasi dan diklasifikasi, yang dijelaskan sebagai berikut :

1. Variabel bebas ( independent variabel ) adalah redesain bantal menyusui.

2. Variabel tergantung (dependent variabel) meliputi :
a. Motivasi menyusui
b. Kepuasan bayi setelah menyusui.
c. Kelelahan ibu
d. Keluhan muskuloskeletal.

3. Variabel kontrol terdiri dari :

a. Aspek subjek meliputi ibu post partum, umur ibu, jumlah gravida, antropometri ibu ( tinggi badan dan tinggi siku duduk, rentang dari siku ke siku ).

b. Aspek organisasi meliputi : waktu/ lama dan interval menyusui.

c. Aspek lingkungan meliputi : kelembaban udara, kebisingan dan pencahayaan.

Data diolah dan dianalisis dengan menggunakan komputer dengan program SPSS (Statistical Package For The Social Sciences) versi 16 for windows, untuk menguji hipotesis yang telah ditetapkan, dalam penelitian ini data terdiri dari kondisi karakteristik subjek, kondisi lingkungan, motivasi menyusui, kepuasan bayi, kelelahan dan keluhan musculoskeletal yang dianalisis dengan cara sebagai berikut :

1. Analisis deskriptif, diperoleh rerata, simpang baku, dan rentangan untuk memberikan gambaran secara deskriptif tentang karakteristik data yang didapat dari hasil penelitian.

2. Data antropometri diperoleh rerata, simpang baku dan persentil.

3. Uji normalitas data terhadap data karakteristik, subjek, kondisi lingkungan, motivasi, kelelahan dan keluhan muskuloskeletal tiap kelompok untuk melihat distribusi data sampel sebelum dan sesudah menyusui dengan menggunakan $U j i$ Shapiro-Wilk ( $\mathrm{N}>50$ ) dimaksudkan untuk menyakinkan bahwa sampel benar-benar berasal dari populasi yang berdistribusi normal kriteria pengujian menggunakan taraf signifikansi $5 \%$ $(\alpha=0.05)$.

4. Uji homogenitas digunakan untuk menyakinkan bahwa sampel memiliki varian yang homogen atau data berasal dari populasi-populasi dengan varian yang sama. Data karakteristik subjek, kondisi lingkungan, motivasi menyusui, kelelahan dan keluhan muskuloskeletal serta beban ibu saat menyusui, data antar kelompok dianalisis dengan menggunakan uji levene's Tes. Kriteria pengujian menggunakan taraf signifikansi $5 \%$ $(\alpha=0.05)$.

5. Uji komparabilitas data yaitu membandingkan data awal sebelum diberikan perlakuan. Yang diuji menggunakan t-Independent Sampels Test kriteria pengujian menggunakan taraf signifikansi 5\% $(\alpha=0.05)$.

6. Uji Efek Perlakuan ( uji beda) dimaksudkan untuk mengetahui perbedaan antara kelompok kontrol dan perlakuan, pada masing-masing variabel

\section{Hasil dan Pembahasan}

\section{Karakteristik Subyek.}

1. Umur Subyek

Dari umur subjek terbesar yaitu pada umur 21 sampai 30 tahun yaitu 10 orang $(90,90 \%)$ untuk jumlah persalinan terbesar pada persalinan pertama yaitu 7 kali $(63,63 \%)$ dan jenis persalinan yang paling banyak adalah persalinan dengan sectio caesaria sebanyak 7 persalinan $(63,63 \%)$.

Rentang umur subjek adalah 21-35 tahun. Rentangan umur yang aman untuk melahirkan, menurut Grandjean (2000), umur akan berpengaruh terhadap kemampuan kerja fisik atau kekuatan otot, dimana kemampuan fisik maksimal baik laki-laki maupun perempuan akan semakin 
menurun seiring dengan bertambahnya umur. Kemampuan fisik maksimal akan dicapai pada umur antara 25 sampai dengan 35 tahun. Umur 21-35 tahun adalah umur yang paling ideal untuk menyusui, resiko terjadinya gangguan kesehatan yang dialami oleh ibu sangat rendah, dan perkembangan tingkat kematangan ibu sudah lebih matang pada umur ini, dimana pada umur ini memiliki tingkat kematangan reproduksi, tingkat emosional, atau bahkan aspek sosial. Menurut Manuaba (1998) kehamilan pada umur di bawah 20 tahun mempunyai risiko : (1) Anemia (2) Gangguan tumbuh kembang janin (3) Keguguran, prematuritas, atau BBLR (4) Gangguan persalinan (5) Preeklampsi (6) Perdarahan antepartum. Kematian maternal pada umur di bawah 20 tahun dua sampai lima kali lebih tinggi dari pada umur 20 sampai 29 tahun menurut Sarwono (2008).

2. Jumlah Persalinan.

Data jumlah persalinan pada kelompok kontrol untuk persalinan pertama sebanyak 7 , persalinan kedua 3 kali dan persalinan ketiga $1 \mathrm{kali}$, data pada kelompok kontrol juga sama yaitu persalinan pertama sebanyak 7 , persalinan kedua 3 kali dan persalinan ketiga 1 kali. Jumlah persalinan subjek dalam penelitian ini adalah satu sampai dengan tiga kali. Keluarga Berencana (Family Planning, Planned Parenthood) suatu usaha untuk menjarangkan atau merencanakan jumlah dan jarak kehamilan dengan memakai kontrasepsi menurut BKKBN (1999). Yang mempunyai tujuan : memperbaiki kesehatan dan kesejahteraan ibu, anak, keluarga dan bangsa; mengurangi angka kelahiran untuk menaikkan taraf hidup rakyat dan bangsa; memenuhi permintaan masyarakat akan pelayanan $\mathrm{KB}$ yang berkualitas, termasuk upaya-upaya menurunkan angka kematian ibu, bayi, dan anak serta penanggulangan masalah kesehatan reproduksi.

\section{Jenis Persalinan}

Data jenis persalinan pada kelompok kontrol untuk persalinan spontan sebanyak 4, persalinan dengan section caesaria sebanyak 7 untuk jenis persalinan kelompok perlakuan sama persalinan spontan sebanyak 4 persalinan dengan section caesaria sebanyak 7 .

Jenis persalinan dalam penelitian ini adalah (1) persalinan spontan dan (2) persalinan dengan Sectio Caesarea. menurut Sarwono (2008) Kelahiran adalah proses membuka dan menipisnya serviks, dari janin turun ke dalam jalan lahir. Macam-macam persalinan berdasarkan cara pengeluarannya.

\section{Data Antropometri Subjek}

Antropometri subjek yang diukur meliputi tinggi badan ibu, tinggi siku pada posisi istirahat, rentang dari siku ke siku. Pengukuran antropometri subjek tersebut berkaitan dengan alat yang akan dirancang yaitu desain bantal menyusui yang baru bagi ibu menyusui. rerata data antropometri subjek pada kelompok kontrol dalam penelitian ini adalah : tinggi badan ibu $155,64 \mathrm{~cm} \pm 2,618$, tinggi siku pada posisi duduk $21,18 \mathrm{~cm} \pm 1,250$ dan rentang dari siku ke siku 41,36 $\mathrm{cm} \pm 1,286$. Sedangkan kelompok perlakuan : tinggi badan $157,64 \mathrm{~cm} \pm 4,567$, tinggi siku pada posisi duduk $21,73 \mathrm{~cm} \pm 1,421$ dan rentang dari siku ke siku 42,45cm $\pm 1,508$.

Rerata tinggi siku pada posisi istirahat/duduk sebesar $22 \mathrm{~cm}$ dipakai untuk menentukan desain tinggi bantal menyusui yang baru, dalam penelitian ini ditetapkan pada persentil 50, berdasarkan pengukuran lainnya maka desain lebar bantal yang diambil dari dimensi rentang dari siku ke siku sebesar $50 \mathrm{~cm}$ pada pesentil 95, tujuan penggunaan nilai persentil 95 adalah agar pada postur ibu yang lebih besar dapat menggunakan bantal ini. Berdasarkan pengamatan dan analisis terhadap ibu menyusui baik yang menggunakan bantal menyusui yang lama maupun menggunakan bantal yang sudah 
diredesain, anggota gerak yang paling banyak digunakan adalah bagian tubuh atas yang digunakan merangkul dan memegang bayi sehingga tinggi bantal yang dirancang $22 \mathrm{~cm}$ dan lebar bantal dirancang $50 \mathrm{~cm}$.

Penelitian yang melibatkan tinggi siku duduk dalam perancangan bantal menyusui dapat dilihat pada hasil penelitian Prihantara (2012) yang melaporkan lebar bantal bayi dirancang berdasarkan rentang siku ke siku, berdasarkan analisa ergonomi diperoleh ukuran lebar bantal adalah 47,45 $\mathrm{cm}$ toleransi sebesar $4,7 \mathrm{~cm}$ ini dengan pertimbangan agar ibu lebih nyaman saat menyusui. dengan demikian rentang siku ke siku hampir subjek penelitian hampir sama dengan rentang siku ke siku di tempat lainnya di wilayah Bali. Penggunaan redesain bantal pada ibu menyusui di tempat penelitian dapat mengurangi keluhan setelah menyusui, ini berdasarkan wawancara didapat bahwa ibu menyusui merasakan kenyamanan saat menggunakan bantal saat menyusui.

\section{Kondisi Lingkungan Tempat Menyusui.}

Kondisi lingkungan yang diukur meliputi kebisingan, kelembaban dan pencahayaan. rerata kondisi lingkungan pada kelompok kontrol yaitu : kebisingan lingkungan tempat ibu menyusui sebesar adalah 51,45 $\pm 1,036$ kelembaban udara di lingkungan $\mathrm{ibu}$ menyusui sebesar $62,73 \pm 1,421$ dan rerata pencahayaan lingkungan tempat ibu menyusui sebesar $26,36 \pm 2,541$ sedangkan pada kelompok perlakuan kebisingan lingkungan sebesar adalah 51,55 $\pm 1,368$ kelembaban udara di lingkungan ibu menyusui sebesar $62,82 \pm 1,328$ dan rerata pencahayaan lingkungan tempat ibu menyusui sebesar $23,64 \pm 1,912$.

\section{Kebisingan.}

Kebisingan adalah terjadinya bunyi yang tidak dikendaki sehingga menganggu atau membahayakan kesehatan. Pengukuran kebisingan pada penelitian menggunakan sound level meter pada kelompok kontrol dan perlakuan, diperoleh rerata kebisingan sebesar 51,5 db, dalam batas normal. Di dalam Keputusan Menteri Kesehatan RI Nomor 1204 Tahun 2014, tentang Persyaratan Lingkungan Kesehatan Rumah Sakit tingkat kebisingan untuk rumah sakit antara $40-80 \mathrm{db}$. Bunyi dikatakan bising apabila melebihi ambang kebisingan yaitu $85 \mathrm{db}$, sumber kebisingan pada penelitian ini berasal dari suara percakapan antar subyek, dapat disimpulkan bahwa tingkat kelembaban ruang menyusui masih dalam batas normal.

2. Pencahayaan.

Pencahayaan merupakan jumlah penyinaran pada suaru bidang kerja yang ada di dalam rumah sakit yang diperlukan untuk melaksanakan kegiatan yang efektif. Sumber pencahayaan pada lokasi penelitian berasal dari cahaya lampu TL, rerata intensitas penerangan yang diukur dengan menggunakan lux meter pada kelompok kontrol dan kelompok perlakuan adalah 23,45 $\pm 1,535$ luks. Dalam Keputusan Menteri Kesehatan RI Nomor 1204 Tahun 2014, tentang Persyaratan Lingkungan Kesehatan Rumah Sakit, besarnya intensitas penerangan yang digunakan dalam pelayanan di rumah sakit sebesar 100 sampai dengan 200 luxmeter, sedangkan untuk ruang perawatan pasien maksimal 50 luxmeter, dengan rerata pencahayaan 23-24 luks di tempat penelitian dalam batas normal.

3. Kelembaban udara.

Kelembaban udara adalah tingkat kebasahan udara, konsentrasi uap air di udara. Berdasarkan Keputusan menteri kesehatan RI Nomor 1204/Menkes/SK/X/2014 tentang persyaratan lingkungan kesehatan rumah sakit, bahwa syarat kelembaban di ruang bersalin adalah 40-70\% untuk kelembaban di ruang menyusui berkisar $63,05 \% \pm 1,52$ dapat disimpulkan bahwa tingkat 
ISSN Print : $1411-951 \mathrm{X}$, ISSN Online : 20503-1716

Jurnal Ergonomi Indonesia

(The Indonesian Journal of Ergonomic)

kelembaban ruang menyusui masih dalam batas normal.

\section{Variabel Motivasi.}

Data motivasi ibu menyusui diukur berdasarkan skor dari kuisioner 30 item kelelahan ( point 11 sampai dengan 20). Dalam penelitian untuk variabel motivasi pengambilan data dilakukan sebelum dan setelah ibu menyusui dengan bantal lama pada kelompok kontrol dan bantal desain baru pada kelompok perlakuan.

Data variabel motivasi dalam penelitian diuji normalitas dengan Shapiro-Wilk Test $(n<50)$, menunjukan data berdistribusi normal $(p>0,05)$. Sedangkan uji homogenitas terhadap variabel motivasi diujikan dengan levene's test untuk mengetahui homogenitas pada masingmasing kelompok. Analisis.

Uji komparabilitas motivasi sebelum menyusui antar kelompok kontrol maupun perlakuan tidak ada perbedaan $(\mathrm{p}>0.05)$, dengan nilai $\mathrm{t}=0,822$ dan nilai $\mathrm{p}=0,421$ Artinya motivasi ibu sebelum menyususi pada kelompok kontrol dan kelompok perlakuan adalah sama.

Uji Beda Motivasi

Hasil uji beda motivasi menggunakan uji $t$ paired, didapatkan hasil ada perbedaan bermakna karena nilai $\mathrm{p}$ lebih kecil dari $0,05(p<0,05)$ hal ini berarti bahwa ada perbedaan motivasi menyusui antar kelompok kontrol dan kelompok perlakuan.

Motivasi adalah sesuatu yang mendorong atau mendorong seseorang bertingkah laku untuk mencapai tujuan tertentu. Berdasarkan hasil penelitian didapatkan bahwa rerata beda motivasi ibu kelompok kontrol $1,90 \pm 0,530$ sedangkan rerata beda motivasi ibu kelompok perlakuan $3,09 \pm 1,044$. Perubahan motivasi ibu pada kedua kelompok bisa disebabkan karena penggunaan bantal menyusui membuat ibu merasa nyaman selama menyusui. Lama ibu menyusui bayinya rata-rata 20 sampai dengan 30 menit untuk masing-masing payudara, dengan jarak waktu antar menyusui kurang lebih dua sampai tiga jam, pada waktu ibu menyusui dengan menggunakan bantal menyusui tangan yang menyangah bayi akan ditopang oleh bantal sehingga terjadi peningkatan motivasi sebesar $3 \%$, penggunaan redesain bantal pada ibu menyusui dapat membuat posisi/ sikap menyusui menjadi nyaman saat menyusui, sehingga mendorong ibu untuk menyusui lebih lama.

Penelitian tentang persepsi dan motivasi ibu tentang pemberian ASI yang dilakukan Hidayanti (2014) menunjukkan bahwa ada hubungan antara peserpsi dan motivasi ibu mengenai pemberian ASI kepada bayinya secara eksklusif pada masyarakat pedesaan menunjukan hasil 0,031 dapat diartikan bahwa persepsi dan motivasi ibu dalam menyusui bayi memberikan kontribusi sebesar $31 \%$ terhadap pemberian ASI secara eksklusif pada masyarakat di wilayah pedesaan

\section{Variabel Kepuasan Bayi}

Data diukur berdasarkan lembar observasi bayi yang meliputi : berat bayi, kondisi bayi tertidur setelah menyusu, jumlah buang air kecil, jumlah buang air besar serta kondisi payudara.

Pengambilan data untuk kepuasan bayi dilakukan satu hari setelah menyusui baik pada kelompok kontrol dan kelompok perlakuan. Uji normalitas menggunakan Shapiro-Wilk Test $(n<50)$, menunjukan data berdistribusi normal $(\mathrm{p}>0.05)$. Sedangkan uji homogenitas terhadap variabel kepuasan bayi diujikan dengan levene's test untuk mengetahui homogenitas pada masing-masing kelompok, hasil analisis data motivasi normal ( $\mathrm{p}>0,05)$. Uji komparabilitas pada variabel kepuasan bayi dengan uji $t$ independent untuk mengetahui kondisi awal bayi antara kelompok kontrol dan perlakuan

Uji beda kepuasan bayi pada kelompok kontrol dan perlakuan, diuji menggunakan uji t-paired. Analisis kepuasan bayi menyusui menunjukan ada 
(The Indonesian Journal of Ergonomic)

perbedaan bermakna karena nilai $\mathrm{p}$ lebih kecil dari $0,05(p<0,05)$ hal ini berarti bahwa ada perbedaan kepuasan bayi pada kelompok kontrol dan kelompok perlakuan

Berdasarkan hasil analisis pada varibel kepuasan bayi dapat dijelaskan sebagai berikut :

Kondisi bayi yang meliputi selisih berat badan lahir dan satu hari sesudah bayi menyusui, apakah tertidur setelah menyusui, jumlah buang air kecil dan buang air besar dalam 24 jam serta kondisi payudara setelah menyusui.

Terjadinya peningkatan kepuasan bayi pada kelompok perlakuan dapat diartikan terjadi bahwa bayi cukup mendapatkan ASI, ini dapat disebabkan karena terjadi kenyamanan ibu saat menyusui bayinya. Kepuasan bayi setelah menyusui yang diukur terjadi perubahan sebesar 1,27\% antara kelompok kontrol dan perlakuan, rendahnya perubahan tingkat kepuasan bayi dapat disebabkan waktu pengambilan data yang pendek yaitu satu hari setelah melahirkan.

\section{Berat Badan Bayi}

Berat badan bayi pada minggu pertama setelah kelahirannya, bayi akan mengalami penurunan berat badannya sekitar 10\% (sepuluh persen) dari berat pada saat dilahirkannya, keadaan kemudian merupakan fisiologis. Penurunan berat badan bayi dikatakan normal karena tubuh bayi banyak mengandung air yang akan dikeluarkan melalui urine setelah lahir kehilangan berat badan sekitar $5 \%$ hingga $10 \%$.

2. Pola Tidur Bayi.

Pola tidur bayi berbeda-beda sesuai dengan tingkatan umurnya. Bayi biasanya memiliki pola tidur yang lebih lama dibandingkan dengan orang dewasa maupun dengan anak-anak dan batita. Menurut artikel bidanmu Pola tidur bayi yang usianya $0-2$ bulan sekitar 16 jam per hari dengan perkiraan : tidur siang sebanyak 7,5 jam dan tidur malam sebanyak 8,5 jam. Bayi dalam usia ini akan menghabiskan waktunya dengan banyak tidur daripada untuk beraktivitas.

3. Jumlah Buang Air Besar dan Buang Air Kecil.

Eliminasi merupakan proses pembuangan. Pemenuhan kebutuhan eliminasi terdiri dari kebutuhan kebutuhan eliminasi uri (berkemih). Usia bukan hanya berpengaruh pada eliminasi urine saja, tetapi juga berpengaruh terhadap kontrol eliminasi itu sendiri. Anak-anak masih belum mampu untuk mengontrol buang air besar maupun buang air kecil karena sistem neuromuskulernya belum berkembang dengan baik. (Nursalam, 2006) Pola buang air besar (BAB) pada bayi sangat bervariasi, antara empat sampai enan kali tiap harinya, ada juga hanya satu kali setiap tiga sampai empat hari, ketika bayi beranjak satu bulan, maka frekeuensi buang air besar kurang dari empat kali setiap harinya.

4. Kondisi Payudara

Hisapan payudara ibu oleh bayi yang benar akan menyebabkan bayi akan meningkatkan kepuasan bayi dan payudara ibu melunak.

Dalam your guide to breastfeeding (2016) Asi awal mengandung kolostrum yang kaya akan nutrisi dan antibodi untuk melindungi bayi. ASI lebh mudah dicerna oleh bayi dibandingkan susu formula, dengan menyusui akan memberikan kesan yang baik bagi ibu dan bayi, karena dengan menyusui terjadi kontak fisik bayi baru lahir dan ibu, merasa lebih aman, hangat dan nyaman. Kontak fisik dapat meningkatkan produksi oksitosin yaitu hormon yang membantu menghasilkan ASI.

Hasil penelitian Fitriani (2015) menunjukkan bahwa pemakaian breastfeeding pillow berpengaruh terhadap kenyamanan ibu dan kepuasan bayi dalam proses menyusui $(\mathrm{p}<0,05)$ dimana sebanyak $20 \mathrm{ibu}(100 \%)$ dengan kategori nyaman dengan memakai breastfeeding pillow pada proses menyusui dan sebanyak 19 bayi (95\%) dengan kategori puas 
dengan memakai breastfeeding pillow pada proses menyusui

Kepuasan bayi setelah menyusui yang diukur terjadi perubahan sebesar $1,27 \%$.

\section{Variabel Kelelahan Ibu Menyusui.}

Data kelelahan didapat dari kuisioner 30 item kelelahan. pengambilan data dilakukan sebelum dan setelah ibu menyusui pada kelompok kontrol dan perlakuan. Uji normalitas dengan ShapiroWilk Test $(n<50)$, menunjukan data berdistribusi normal $(\mathrm{p}>0.05)$. Sedangkan uji homogenitas dengan levene's test hasil analisis data motivasi adalah normal $(p>0,05)$. Sedangkan uji komparabilitas menunjukan tidak ada perbedaan $(\mathrm{p}>0.05)$, dengan nilai $\mathrm{t}=0,000$ dan nilai $\mathrm{p}=1,000$ artinya tingkat kelelahan ibu sebelum menyusui antar kelompok adalah sama. Untuk uji beda kelelahan menggunakan uji t-paired. hasil analisis uji beda pada variabel kelelahan antar kelompok menunjukan hasil bahwa ada perbedaan bermakna karena nilai $p$ lebih kecil dari $0,05(\mathrm{p}<0,05)$ Hasil analisis berdasarkan kuisioner 30 item kelelahan secara diskriptif dapat dijelaskan bahwa dari 30 jenis pertanyaan tentang kelelahan pada ibu setelah menyusui, yang disampaikan oleh ibu setelah menyusui adalah berdasarkan pertanyaan : Ibu merasa sering menguap.

1. Ibu merasa mengantuk.

2. Ibu merasa ingin berbaring

3. Ibu merasa susah berpikir.

4. Ibu tidak bisa berkonsentrasi.

5. Ibu kurang percaya diri.

6. Ibu merasa kaku di bahu

7. Ibu merasa nyeri di punggung.

8. Ibu merasa haus.

Kelelahan merupakan suatu mekanisme perlindungan agar tubuh terhindar dari kerusakan lebih lanjut, dan dapat terjadi pemulihan setelah istirahat. Permasalahan yang sering kali terjadi pada ibu baru setelah melahirkan adalah permasalahan terkait dengan proses persalinan, kemudian aktivitas yang berhubungan dengan menyusui dan masalah nifas. Ibu menyusui seringkali mengalami rasa lelah, hal ini wajar dialami akan tetapi apabila terus berlanjut akan mempengaruhi dalam merawat bayi. Ketidaknyamanan dari rasa lelah yang berkepanjangan akan membuat ibu mengalami kesulitan dalam beradaptasi dalam membesarkan bayi. Kelelahan setelah menyusui terjadi dalam dua sampai tiga minggu pertama setelah melahirkan. Tingkat kelelahan ibu setelah menyusui yang diukur setelah menggunakan bantal menyusui mengalami penurunan sebesar $5,73 \%$ hal ini menunjukan bahwa intervensi ergonomi yang dilakukan mampu menurunkan tingkat kelelahan ibu menyusui.

Penelitian tentang kelelahan oleh Indriana (2010) tentang pengaruh kelelahan otot terhadap ketelitian kerja didapatkan kelelahan sangat berpengaruh terhadap penurunan ketelitian kerja sebesar $4,4 \%$

Penelitian tentang kelelahan lainnya yang dilakukan Sundari (2008) bahwa intervensi ergonomi pada pengolahan tanah bahan keramik dapat mengurangi kelelahan sebesar $60,98 \%$, penelitian ini didukung juga oleh temuan Adiatmika (2007) yang mengatakan bahwa pengaruh kondisi kerja dengan pendekatan ergonomic total dapat menurunkan kelelahan sebesar $6,79 \%$.

\section{Variabel Keluhan Muskuloskelatal Ibu Menyusui}

Data keluhan muskuloskelatal ibu menyusui didapatkan berdasarkan skor dari kuisioner Nordic Body Map. Uji normalitas dengan Shapiro-Wilk Test $(n<50)$, menunjukan data berdistribusi normal $\quad(\mathrm{p}>0.05)$. Sedangkan uji homogenitas terhadap dengan levene's test hasil analisis data normal $(\mathrm{p}>0,05)$. uji komparabilitas menunjukan tidak ada perbedaan $(\mathrm{p}>0.05)$, dengan nilai $\mathrm{t}=$ 0,976 dan nilai $p=0,341$. Artinya kondisi awal tingkat keluhan muskuloskeletal ibu menyusui antar kelompok adalah sama 
Uji beda kelelahan menggunakan uji t-paired hasil analisis menunjukan hasil ada perbedaan bermakna karena nilai $p$ lebih kecil dari $0,05 \quad(\mathrm{p}<0,05)$ hal ini berarti bahwa ada perbedaan tingkat keluhan muskuloskelatal ibu setelah menyusui antar kelompok. Hasil analisis keluhan muskuloskeletal berdasarkan kuisioner nordic body map secara diskriptif dari 28 jenis pertanyaan tentang keluhan muskuloskeletal pada ibu setelah menyusui, keluhan yang disampaikan oleh ibu setelah menyusui adalah berdasarkan pertanyaan :

1. Sakit/kaku di leher atas.

2. Sakit/kaku di leher bawah.

3. Sakit/kaku dibagian bahu kiri.

4. Sakit/kaku dibagian bahu kanan.

5. Sakit di lengan atas kiri.

6. Sakit di lengan atas kanan.

7. Sakit di punggung.

8. Sakit di lengan bawah kiri.

9. Sakit di lengan bawah kanan.

Berdasarkan hasil analisis dijelaskan sebagai berikut :

Keluhan muskuloskeletal adalah gangguan pada bagian otot skeletal yang disebabkan oleh karena otot menerima beban statis secara berulang dan terus menerus dalam jangka waktu yang lama Data keluhan muskuloskelatel antar kelompok menunjukkan ada perbedaan bermakna $(p>0.05)$, dengan $t=7,546$ dan nilai $\mathrm{p}=0.0001$ Artinya ada perbedaan keluhan muskuloskelatel

Keluhan ini dirasakan mulai dari keluhan sangat ringan sampai sangat sakit, ini terjadi apabila otot menerima beban statis secara berulang dan dalam waktu yang lama. penggunaan desain baru bantal menyusui akan membuat posisi ibu yang nyaman saat menyusui, ini akan mengurangi peregangan otot saat menyusui sehingga dapat membantu ibu untuk menjaga kondisi fisik selama proses menyusui.

Lebih lanjut menurut Pheasent (1991) bahwa pembebanan statis dan paksa dapat menyebabkan aliran darah terhambat sehingga suplai oksigen ke bagian otot tidak cukup. Penelitian yang dilakukan Rakhmadhany (2013) menunjukkan hasil ibu menyusui akan mengalami keluhan muskuloskeletal sebesar $88,6 \%$ yang dipengaruhi oleh faktor kesegaran jasmani ibu menyusui.

Penelitian tentang keluhan musculoskeletal oleh Richard (2013) yang menyatakan bahwa redesain alat kerja terjadi penurunan keluhan muskuloskeletal sebesar 30,63\%, demikian juga dengan penelitian Adiatmika (2007) yang menyebutkan perbaikan konsidi kerja dengan pendekatan ergonomic total dapat menurunkan keluhan musculoskeletal sebesar 5,24\%.

Berdasarkan hasil penelitian, hasil analisis setelah meredesain bantal menyusui terjadi penurunan keluhan muskuloskelatal sebesar $6,36 \%$ dan perbedaan bermakna $(\mathrm{P}>0,05)$, dengan demikian dapat dikatakan bahwa penggunaan redesain bantal menyusui yang mengacu pada aspek antropometri dengan menambah ketinggian bantal terbukti mengurangi keluhan muskuloskeletal dan posisi menyusui menjadi nyaman

\section{Kesimpulan dan Saran}

Simpulan.

Bertitik tolak dari hasil analisis dan pembahsan di atas, dapat disimpulkan sebagai berikut :

1. Penggunaan redesain bantal menyusui meningkatkan motivasi ibu untuk menyusui bayi sebesar 3,00\%

2. Penggunaan redesain bantal menyusui meningkatkan kepuasan menyusui bayi sebesar $1,18 \%$

3. Penggunaan redesain bantal menyusui dapat mengurangi kelelahan pada ibu menyusui sebesar 5,73\%.

4. Penggunaan redesain bantal menyusui dapat mengurangi keluhan muskuloskeletal pada ibu menyusui sebesar $6,36 \%$. 
ISSN Print : $1411-951 \mathrm{X}$, ISSN Online : 20503-1716

Jurnal Ergonomi Indonesia

(The Indonesian Journal of Ergonomic)

Saran

1. Telah terbukti bahwa redesain bantal menyusui meningkatkan motivasi, meningkatkan kepuasan bayi menyusui, mengurangi kelelahan dan mengurangi keluhan muskuloskeletal pada ibu menyusui sehingga disarankan kepada ibu menyusui untuk menggunakan redesain bantal untuk mengurangi keluhan yang ditimbulkan akibat proses menyusui.

2. Hasil penelitian dapat dipakai sebagai acuan bagi penelitian sejenis dan bagi peneliti bisa juga dikembangkan ke arah yang lebih mendalam.

\section{Daftar Pustaka}

Adiputra, I.N. 2002. Denyut Nadi dan Kegunaannya dalam Ergonomi. Jurnal Ergonomi Indonesia. Vol 3 No 16: 22-26.

Adiatmika, IP.G. 2007 “ Perbaikan Kondisi Kerja Dengan Pendekatan Ergonomi Total Menurunkan Keluhan Muskuloskeletal Dan Kelelahan Serta Meningkatkan Produkrivitas Dan Penghasilan Perajin Pengetan Logam di Kediri Tabanan "Jurnal Ergonomi Indonesia. Denpasar : Program Pasca Sarjana Universitas Udayana.

Anonim, 1999. BKKBN Kependudukan $K B$ dan KIA. Bandung, Balai Litbang.

Anonim, 2014. Keputusan Menteri Kesehatan RI Nomor 1204 Tahun 2014, tentang Persyaratan Lingkungan Kesehatan Rumah Sakit

Bakta, I.M. 1997. Makalah Rancangan Penelitian. Penataran Sehari: Tentang Metodelogi Penelitian. Denpasar : Fakultas Kedokteran Universitas Udayana.

Doenges, Marylinn E, 2001. Rencana asuhan Maternal/Bayi. Jakarta : EGC
Fahmi, I. 2014. Perilaku Organisasi. Teori, Aplikasi Dan Kasus: Bandung ALFABETA, CV.

Llewellyn, D.2009. Setiap Wanita, Dellapratasa Publishing.

Grandjean, E. 1988. Fitting The Task To The Man. A Textbook Of Occupational Ergonomics, London Taylor \& Francis Ltd.

Hendrick, H.W and Kleiner, M.B. 2002. Macroergomonic Theory, Methods, and Applications. Lawrence Erlbaum, Inc., Publishers, Mahwah, New Jersey

Iridiastadi, H. 2014. Ergomoni Suatu Pengantar : Bandung. PT. Remaja Rosda Karya.

Julius, P dan Martin Z, 2003. Dimensi Manusia \& Ruang Interior : Jakarta, PT Erlangga.

Manuaba, I.B.A. 1992a. Pengaruh Ergonomi terhadap Produktiviats. Bunga Rampai Ergonomi Vol, 1. Program Studi Ergonomi Fisiologi Kerja . Denpasar ; Universitas Udayana.

Manuaba, A. 1999. Penerapan Ergonomi Partisipasi dalam Meningkatkan Kinerja Industri. Makalah. Disampaikan pada Seminar Nasional Ergonomi, Reevaluasi Penerapan Ergonomi dalam Meningkatkan Kinerja Industri. Surabaya 23 November

Manuaba, A. 2000. Ergonomi Meningkatkan Kinerja Tenaga Kerja dan Perusahaan. Dalam : Hermansyah. editor. Prosiding Simposium dan Pameran Ergonomi Indonesia 2000. Bandung: ITB Press. h. 11-19 
ISSN Print : $1411-951 \mathrm{X}$, ISSN Online : 20503-1716

Jurnal Ergonomi Indonesia

(The Indonesian Journal of Ergonomic)

Manuaba, I.B.A. 2005. Ergonomi Dalam Industri : Universitas Udayana Kampus Bukit Jimbaran.

Manuaba, I.B.G. 1998. Ilmu Kebidanan,Penyakit Kandungan dan Keluarga Berencana untuk Pendidikan Bidan : Jakarta: EGC.

Mochtar, R. 1998. Sinopsis Obstetri, Obstetri Fisiologis, Obstetri Patologis : Jakarta EGC.

Maryunani, A. 2010. Ilmu Kesehatan Anak dalam Kebidanan. Jakarta. Trans Info Media.

Marni dan Kukuh R, 2012. Asuhan Neonatus, Bayi, Balita Dan Anak Pra Sekolah. Yogyakarta. Pustaka Pelajar.

Myles, 2009. Buku Ajar Bidan (Myles Textbook For Midwives ) Edisi 14. : Jakarta EGC.

Nurmianto, E.1996. Ergomoni Konsep Dasar dan Aplikasinya. Jakarta : PT Guna Widya.

Nursalam, 2006. Asuhan Keperawatan pada Pasien dengan Gangguan Sistem Perkemihan. Jakarta : Salemba Medika

Nursingbegin, 2011. Denyut Nadi Normal Manusia, ( citied 2013 November 20), Available From:http: //Nursingbegin.com/Denyut-NadiNormal-Manusia

Roesli, U. 2009. Panduan Praktis Menyusui: cetakan 1: Jakarta. Pustaka Bunda.

Saifuddin AB, 2001. Buku Acuan Nasional Pelayanan Kesehatan Maternal dan Neonatal, Jakarta : JNPKKR POGI.
Siregar, S. 2014. Statistik Parametrik. Untuk Penelitian Kualitatif : Jakarta Bumi Aksara.

Suherni, 2009. Perawatan Masa Nifas: Yogyakarta Fitramaya.

Sutarman, 1972. Penerapan Ergonomi di Perusahaan : Jakarta. Majalah Hiperkes dan Keselamatan Kerja.

Sutarna, 2011. "Aplikasi Ergonomi Pada Proses Pemotongan Pelat Eser Meningkatkan Kinerja Mahasiswadi Bengkel Teknologi Mekanikpoliteknik Negeri Bali," (tesis) Denpasar: Program Pascasarjana Universitas Udayana

Sutajaya, IM. 2006. Ergonomi Dalam Pembelajaran, Denpasar : Bagian Ilmu Faal Fakultas Kedokteran, Universitas Udayana.

Sutjana, D.P.2003. "Peningkatan Produktivitas Kerja Penyabit Padi Menggunakan Sabit Bergerigi Dibandingkan dengan Sabit Biasa" (tesis) Denpasar: Program Pascasarjana Universitas Udayana

Tawarka. 2013 Ergonomi Industri : Dasar-Dasar Pengetahuan Ergonomi dan Aplikasi di Tempat Kerja. Cetakan kedua : Surakarta : Harapan Press Solo.

Tarwaka, dkk. 2004. Ergonomi untuk Keselamatan dan Kesehatan Kerja dan Produktivitas. Surakarta: UNIPRESS

Tarwaka, Solichul, H.A., Bakri, Lilik, S., 2004, Ergonomi Untuk Keselamatan, Kesehatan Kerja dan Produktivitas, Surakarta: UNIBA Press

Utomo, A. 2012. Gambaran Tingkat Risiko Ergonomi dan Keluhan Gangguan Trauma Komulatif pada 
ISSN Print : $1411-951 \mathrm{X}$, ISSN Online : 20503-1716

Jurnal Ergonomi Indonesia

(The Indonesian Journal of Ergonomic)

Pekerja Pabrik Rahmat Tempe di Pancoran Jakarta Selatan 2011. UI. Depok

Office on Woman's Health. 2011. Your Guide to Breastfeeding. U.S Departement of Health and Human Services, $1 \quad$ (1): 4-5. http://www.womenshealth.gov/publi cations/ourpublications/breastfeeding -guide/from=breastfeeding ( Diakses pada 4 Agustus 2016, pukul 22.00 WITA)

Pheasant, S. 1988. Anthropometry Ergonomics and Design, London : Taylor and Francis, inc.

Pheasant, S. 2003. Bodyspace : Anthropometry Ergonomics and Design of work $2^{d}$ Edition, London : Taylor and Francis, inc

Pocock, S.J. 2008. Clinical Trial A. Practical Approach : the size of clinical trial Hichester: John Wiley \& Sons.

Prawirohardjo, S. 2008. Ilmu Kebidanan. Jakarta :Yayasan Bina Pustaka Sarwono Prawirohardjo.

Prihantara D.F,2012. Perancangan Alat Bantu Menyusui Dengan Pendekatan Ergonomi Menggunakan Metode Quality Function Deploment, Tugas Akhir ): Bandung, Institut Teknolagi Telkom.

Wardani, L.K. 2014. Evaluasi Ergonomi Dalam Perancangan Desain: Surabaya. Fakultas Seni Dan Desain Universitas Petra Surabaya.

Wibowo, A. 2014. Metodelagi Penelitian Praktis, cetakan kedua : Jakarta PT Rajagrafindo Persada.
Wibowo, 2014. Perilaku dalan organisasi, cetakan kedua : Jakarta PT Rajagrafindo Persada.

Wijana, IN 2009. “Pembelajaran Sains Melalui Pendekatan Ergonomi Mengurangi Keluhan Muskuloskeletal, Kebosanan Dan Kelelahan Serta Meningkatkan Motivasi Dan Prestasi Belajar Siswa SD 1 Sangsit Kecamatan Sawan Kabupaten Buleleng," (tesis) Denpasar: Program Pascasarjana Universitas Udayana 